\title{
Effectiveness of Palatal Mucosa Graft in Surgical Treatment of Sub-Glottic Stenosis
}

\author{
Umit Aydogmus ${ }^{1} \cdot$ Adem Topkara $^{2} \cdot$ Metin Akbulut $^{3} \cdot$ Adem Ozkan $^{2} \cdot$ Figen Turk $^{1} \cdot$ Barbaros Sahin $^{4} \cdot$ Gokhan Yuncu $^{5}$ \\ Departments of ${ }^{1}$ Thoracic Surgery, ${ }^{2}$ Plastic, Reconstructive and Aesthetic Surgery, ${ }^{3}$ Pathology, and ${ }^{4}$ Experimental Research Laboratory, Medical \\ Faculty of Pamukkale University, Denizli; ${ }^{5}$ Department of Thoracic Surgery, Liv Hospital, Istanbul, Turkey
}

Objectives. Mucosal free grafts may be successfully applied in many surgical interventions. This study aims at investigating the feasibility of palatal mucosa graft in sub-glottic field in an animal model.

Methods. This randomized prospective controlled study was conducted with an animal model. Sub-glottic inflammation was created in 15 adult rabbits in each group and sub-glottic stenosis surgery was applied thereafter. The rabbits in group 1 (control group) underwent segmental resection, partial cricoidectomy, and trachea-thyroid cartilage anastomosis; the rabbits in group 2 underwent segmental resection, cricoplasty, and crico-tracheal anastomosis using free buccal mucosa graft; and the rabbits in group 3 underwent segmental resection, cricoplasty, and crico-tracheal anastomosis using free palatal mucosa graft. Re-stenosis was evaluated after 42 days.

Results. The percentages of stenosis were $27 \% \pm 20 \%, 40 \% \pm 20 \%$, and $34 \% \pm 23 \%$ for group 1,2 , and 3, respectively and the difference was not statistically significant $(P=0.29)$. Intensive and tight fibrosis was observed in 2 rabbits $(13 \%)$ in group 1, in 5 rabbits (33\%) in group 2, and in 3 rabbits $(20 \%)$ in group 3. There was not a statistically significant difference between groups $(P=0.41)$. Excessive inflammation was observed in 3 rabbits $(20 \%)$ in group 1 , in 7 rabbits $(47 \%)$ in group 2 , and 3 rabbits $(20 \%)$ in group 3 . There was no a statistically significant difference between groups although inflammation rate was higher in the rabbits which underwent buccal mucosa graft $(P=0.18)$.

Conclusion. The surgical treatments applied with free mucosa graft reduced anastomosis tension through enabling anastomosis to the distal of cricoid instead of thyroid cartilage. Free palatal mucosa grafts may be used in sub-glottic field, one of the most challenging fields of trachea surgery, due to ease of application and rapid vascularization.

Keywords. Tracheal Stenosis; Mucosal Tissues; Autografts; Airway; Wound Healing

\section{INTRODUCTION}

Sub-glottic stenosis developing after endo-tracheal tube arises from increased granulation tissue following contact ulcer and this hypertrophic scar tissue is similar with the abnormal wound healing defined as 'keloid' [1]. Treatment of sub-glottic stenosis is more complex when compared with the treatment of the oth-

- Received October 6, 2015

Revised December 8, 2015

Accepted January 12, 2016

- Corresponding author: Umit Aydogmus

Department of Thoracic Surgery, Medical Faculty of Pamukkale University, Denizli 20100,Turkey

Tel: +90-2582906000, Fax: +90-2582906001

E-mail:mdaydogmus@yahoo.com er tracheal stenosis. Surgical treatment methods vary depending on whether vocal cords are mobile and glottic stenosis accompanies [2,3]. Single step repair techniques which include the resection of the stenotic segment and anterior cricoid and anastomosis of trachea with thyroid cartilage are usually effective in the cases in which vocal cords are mobile [4]. Mucosal graft is used and laryngoplasty is applied in laryngo-tracheal fissure technique [5]. Regardless of the surgical repair type, the most important point of the sub-glottic stenosis surgery is regular healing of mucosa, as the source of the problem. The factors which influence the healing of mucosal tissue in anastomosis line include sufficiency of vascular supply and the tension in anastomosis line. Sub-glottic releasing techniques are added to the technique depending on the length of the lesion. However

Copyright $\odot 2016$ by Korean Society of Otorhinolaryngology-Head and Neck Surgery.

This is an open-access article distributed under the terms of the Creative Commons Attribution Non-Commercial License (http://creativecommons.org/licenses/by-nc/4.0)

which permits unrestricted non-commercial use, distribution, and reproduction in any medium, provided the original work is properly cited. 
in some patients, long segment resections may be required until reaching healthy tracheal mucosa for closure with wide mucosal flap from trachea after removal of the affected mucosal tissue as in the technique of Grillo [4]. The tension in anastomosis line may increase as the result of this. Free mucosa grafts may be an alternative in such patients. Unfortunately, no randomized studies are available which show the more effective method are available.

Mucosal free grafts may be successfully applied in many surgical approaches. Buccal mucosa grafts are preferred in trachea surgery $[5,6]$. Palatal graft is preferred in some surgical interventions due to contracture resistance and ease of use [7]. This randomized prospective study aims at investigating the effectiveness of palatal mucosa graft in sub-glottic stenosis in experimental rabbit model, as an alternative to the conventional method.

\section{MATERIALS AND METHODS}

\section{Ethics}

This study was conducted in Animal Tests Laboratory between January 19th, 2015 and June 21th, 2015. This study was conducted after ethics committee approval had been obtained from Animal Local Ethics Committee (PAUHDEK 2014-027). Care and comfort of the animals was provided by an experienced veterinary surgeon in accordance with the international standards. All animals have received humane care in compliance with the 'Principles of Laboratory Animal Care' formulated by the National Society for Medical Research and the 'Guide for the Care and Use of Laboratory Animals' prepared by the Institute of Laboratory Animal Research published by the National Academies Press (1996 version). The animals were sacrificed using intra-cardiac potassium chloride following anesthesia for sub-glottic field sampling.

\section{Population}

A total of 48 white New Zealand rabbits produced at Animal Tests Center, weighing 2,400-3,350 g at the beginning of the test were used in this study. One of the animals was dead after the first procedure, two of the animals were dead after the second procedure in the early period. One rabbit died on day 2 due to hemorrhagic coagulum following stenosis formation opera-

\section{H I G H L I G G H T T S}

- Applying mucosal graft may reduce anastomosis tension in laryngotracheal surgery with extensive segmental resection.

- Excessive inflammation score in the palatal mucosal group (20\%) was less than the buccal group (47\%).

- The stenosis scores were similar between the control group and the mucosal graft groups $(P=0.505)$. tion. One animal in groups 1 and 3 died following sub-glottic surgical intervention on postoperative day 1 and 3, respectively. The study was completed with 15 animals in each group.

\section{Design}

Single dose of $10 \mathrm{mg} / \mathrm{kg}$ cefuroxime was administered via intramuscular route for antibiotic prophylaxis before each procedure. Anesthesia was provided with $35 \mathrm{mg} / \mathrm{kg}$ ketamine and $5 \mathrm{mg} / \mathrm{kg}$ xylazine following 8 hours of fasting. A short-acting local anesthetic $(10 \mathrm{mg} / \mathrm{mL}$ prilocaine) was applied sub-cutaneously at the beginning of the surgical procedure and approximately $0.6-1$ $\mathrm{mL}$ of long-acting local anesthetic $(5 \mathrm{mg} / \mathrm{mL}$ bupivacaine) was applied after the procedure. Bleeding control was provided with a bipolar electrocautery.

\section{Creating stenosis}

The first procedure targeted to create a stenosis in all animals. Intubation was not required as spontaneous respiration continued due to the anesthesia technique which was used. Cervical incision was applied following anesthesia. The second and the third cartilage rings of trachea were removed circularly. Afterwards, the first cartilage ring and the inner surface of the cricoid ring was traumatized using a micro-scissor. Finally, 1th and 4th rings of trachea was sutured continuously using two 5-0 polyglactin (Vicryl; Ethicon Inc., Somerville, NJ, USA) and an endto-end anastomosis was done. The first suture started from the outer surface of the first cartilage, just above the cartilage and membranous surface junction, cartilage ring. Anastomosis was completed with continuous sutures on cartilage surfaces after the anastomosis of membranous surfaces had been completed with continuous sutures.

\section{Surgical techniques}

The second procedure was done 35-40 days after the first procedure. All of the second trachea surgeries were applied by the same surgeon. Mucosal flaps were done by two surgeons. Stenotic segments after the cricoid ring was removed in all animals. The following procedures continued by dividing the rabbits into 3 groups according to Myer-Cotton classification.

Group 1 (control group): After the stenotic ring had been removed, the posterior ring of the cricoid was preserved and the anterior part was removed and the whole fibrotic tissue was excised in accordance with the technique described by Grillo [4]. A membranous flap was prepared from the robust trachea. It was sutured individually using a 6-0 polyglactin suture (Vicryl, Ethicon Inc.) as described in the method. Cartilaginous surface of trachea was sutured individually onto the remaining lateral surfaces of the cricoid ring and onto the inferior surface of thyroid cartilage.

Group 2 (buccal mucosa graft): A simplified modification of sub-glottic stenosis surgery of Montgomery [5] was applied in order to show the effectiveness of mucosa grafts. Differently 
from the technique of Montgomery [5], cartilage graft was applied to only the anterior cricoid surface. The procedure started with the resection of the stenotic trachea segment on distal of cricoids. Afterwards an incision from the anterior of cricoid cartilage to thyroid cartilage was done and traction sutures were applied to both margins. The fibrotic fields within the cricoid cartilage were excised using an elevator and lancet (Fig. 1). The mucosa graft harvested from the cheek was fixed to cricoid ring with a 6-0 polyglactin suture. A continuous suture was done between membranous surface of trachea and cricoid ring (together with mucosal graft) with a 6-0 polyglactin suture. The triangle piece obtained from thyroid cartilage was removed. The cartilage was fixed to the anterior surface of cricoid ring with a 8-0 polyglactin (Vicryl, Ethicon Inc.) suture and the diameter of cricoid ring was enlarged. Cartilaginous surface of trachea and the anterior surface of cricoid were sutured individually and end-toend anastomosis was completed.

Group 3 (palatal mucosa graft): The procedures described for group 2 were done using palatal mucosa graft. The tissue from where palatal mucosa graft was harvested was left to primary healing.

\section{Assessment}

Sacrifice of animals was done on day 42 following the second procedures and glottis and sub-glottic fields were removed. The first assessment was done with macroscopic measurement by three blinded doctors and stenosis grading was done according to Myer-Cotton classification (MCC) [8]. Myer et al. [8] devised a classification scheme for grading circumferential subglottic stenosis from I-IV, endoscopically. MCC scores: (1) class 1, indicates up to $50 \%$ obstruction; (2) class $2,51 \%-70 \%$; (3) class 3 , $71 \%-99 \%$; and (4) class 4 , no detectable lumen.

We calculated the MCC by modifying the endoscopic classification. The first tracheal cartilage was separated from cricoid cartilage. The tissue around the cricoid cartilage was removed until there is alone cartilage at the outer surface. Cricoid carti-
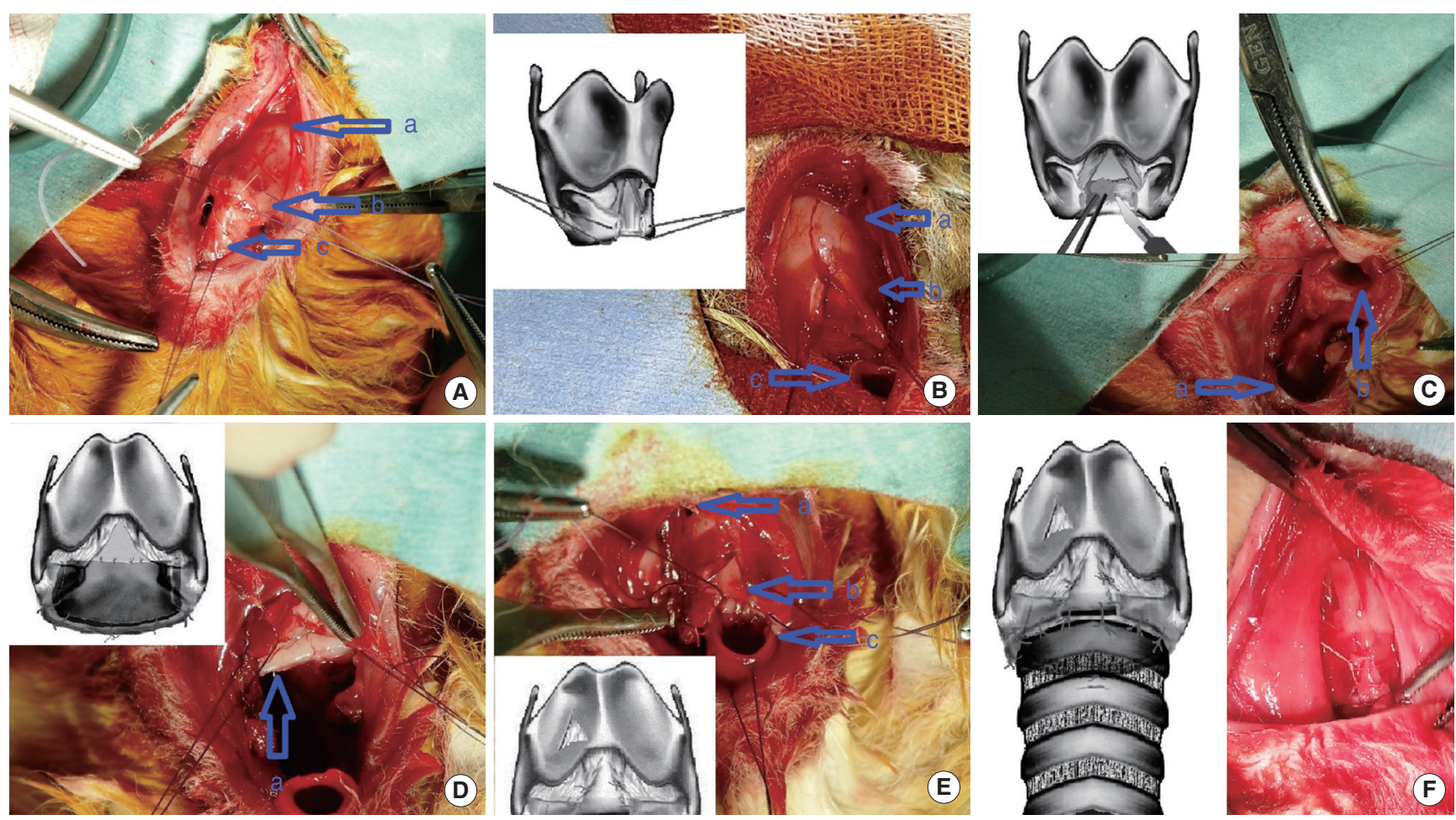

Fig. 1. Sub-glottic stenosis surgery with mucosal graft. (A) Dissection of stenotic trachea segment; (a) thyroid cartilage, (b) cricoid cartilage, (c) stenotik tracheal segment. (B) An incision from the anterior of cricoid cartilage to thyroid cartilage was done and traction suture was applied to both margins after the stenotic tracheal segment had been removed; (a) thyroid cartilage, (b) cricoid cartilage (anterior part of its is divided and traction sutures were applied to both margins), (c) distal trachea. (C) The fibrotic mucosa within the cricoid cartilage were excised; (a) distal trachea, (b) cricoid cartilage (Leaving the posterior plate of cricoid intact. The tracheal lesion and fibrotic mucosa on the cricoid cartilage were completely removed). (D) The mucosa graft was fixed to cricoid ring; (a) cricoid cartilage (The inner surface of the posterior plate of its was completely covered with mucosal graft). (E) A continuous suture was done between membranous surface of trachea and cricoid ring. Then, the triangle piece obtained from thyroid cartilage was removed and the cartilage graft was fixed to the anterior surface of cricoid ring; (a) thyroid cartilage (a triangle piece removed from lateral surface of its), (b) Cricoid cartilage (the cartilage graft was fixed to cricoid), (c) distal trachea (sutured to the plate of cricoid). (F) Cartilaginous surface of trachea and the anterior surface of cricoid were sutured individually and end-to-end anastomosis was completed (The diameter of cricoid ring was enlarged by applying a triangle cartilage graft). 
lage was divided into two rings in the transverse plane. Outer border diameter and inner border diameter of the cricoid cartilage were measured in two axes than averaged. According to the inner border diameter/outer border diameter ratios that was found the lowest in the macroscopic measurement from two section samples, MCC was calculated using the following formula:

\section{MCC $=(1$-inner border diameter/outer border diameter $) \times$ 100}

The second assessment was done by a blinded pathologist and targeted to determine fibrosis and inflammation scores and 5 groups were determined similarly to the study of IniguezCuadra et al. [9].

Fibrosis scoring: (1) score 1, no fibrosis; (2) score 2, mild fibrosis with new onset; (3) score 3, moderate fibrosis (presence of collagen bands and fibroblasts); (4) score 4, intensive fibrosis; and (5) score 5 , very intensive fibrosis.

Inflammation scoring: (1) score 1, no inflammation; (2) score 2 , inflammation in less than $10 \%$ of the fields; (3) score 3, inflammation in less than $30 \%$ of the fields; (4) score 4, intensive inflammation in $30 \%-60 \%$ of the fields; and (5) score 5 , widespread inflammation (more than 60\%).

\section{Statistical analysis}

Minimum number of subjects which could show 50\% positive or negative effect was detected as 45 for Fisher exact test and chi-square test with $\alpha=0.05$ and $\beta=0.2$ (power $=0.8$ ). Fisher exact test and chi-square test were used for comparison of results.
Kruskal-Wallis test was applied for comparison of the medians values of three groups. One way analysis of variance test was used for inter-group comparison of normally distributed numerical data. A $P$-value level of $<0.05$ was accepted as statistically significant.

\section{RESULTS}

Gender $(P=0.92)$, weight $(P=0.66)$, and induced stenosis grade $(P=0.88)$ were similar for the rabbits in each group which underwent sub-glottic stenosis surgery (Table 1). MCC scores following sub-glottic stenosis surgery were as follows for the rabbits in group 1: $12(80 \%)$ in class $1 ; 2(13 \%)$ in class 2 ; and $1(7 \%)$ in class 3 . These values were as follows for the rabbits in group 2 : $9(60 \%)$ in class $1 ; 4(27 \%)$ in class 2 ; and $2(13 \%)$ in class 3. Of the rabbits in group 3 , these values were $11(73 \%), 2(13 \%)$, and $2(13 \%)$, respectively for class 1,2 , and 3 . The difference between groups was not statistically significant $(P=0.5)$ (Table 2). Percentages of stenosis were $27 \% \pm 20 \%, 40 \% \pm 20 \%$, and $34 \% \pm 23 \%$ for group 1,2 , and 3 , respectively, and the difference between groups was not statistically significant $(P=0.29)$ (Fig. 2).

Histopathological images of fibrosis classifications is shown in Fig. 3. In group 1, fibrosis scores 2, 3, 4, and 5 were identifed 9 $(60 \%), 4(27 \%), 1(7 \%)$, and $1(7 \%)$ of the rabbits, respectively. These scores were as follows for the rabbits in group 2: $6(40 \%)$ in scores $2 ; 4(27 \%)$ in scores $3 ; 2(13 \%)$ scores 4 ; and $3(20 \%)$ scores 5 . In group 3 rabbits, these scores were $9(60 \%), 3(20 \%)$, $2(13 \%)$, and 1 (7\%) for scores 2,3 , 4, and 5, respectively. His-

Table 1. Distribution of the characteristics of the rabbits before sub-glottic stenosis surgery

\begin{tabular}{lccc}
\hline Variable & Group 1 & Group 2 & Group 3 \\
\hline Weight $(\mathrm{g})$ & $2,853(2,450-3,350)$ & $2,767(2,400-3,300)$ & $2,847(2,420-3,310)$ \\
Sex & $8(53)$ & $8(53)$ & $7(47)$ \\
$\quad$ Male & $7(47)$ & $7(47)$ & $8(53)$ \\
Female & & & 0.9615 \\
MCS $^{\text {b) }}$ & $12(80)$ & $11(73)$ & $12(80)$ \\
Preoperative=1 & $3(20)$ & $4(27)$ & $3(20)$ \\
\hline
\end{tabular}

Values are presented as median (range) or number (\%).

MCS, Myer-Cotton scores.

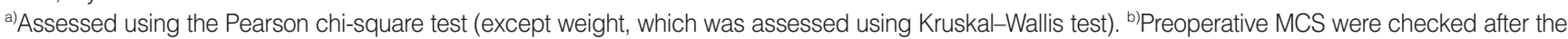
procedure done for creating stenosis, before the sub-glottic surgical technique.

Table 2. Postoperative outcomes among three groups

\begin{tabular}{lccc}
\hline Variable & Group 1 & Group 2 & Group 3 \\
\hline Myer-Cotton scores: $1 / 2 / 3$ & $12 / 2 / 1(80 / 13 / 7)$ & $9 / 4 / 2(60 / 26 / 13)$ & $11 / 2 / 2(73 / 13 / 13)$ \\
Fibrosis score: $2 / 3 / 4 / 5$ & $9 / 4 / 1 / 1(60 / 27 / 7 / 7)$ & $6 / 4 / 2 / 3(40 / 27 / 13 / 20)$ & $9 / 3 / 2 / 1(60 / 20 / 13 / 7)$ \\
Inflammation score: $2 / 3 / 4 / 5$ & $9 / 3 / 2 / 1(60 / 20 / 13 / 7)$ & $5 / 3 / 4 / 3(33 / 20 / 27 / 20)$ & $7 / 5 / 2 / 1(47 / 33 / 13 / 7)$ \\
\hline
\end{tabular}

Values are presented as number (\%).

a) Assessed using the Pearson chi-square test. 
topathological analysis of stenotic lesions for the fibrosis scores revealed similar changes, with no significant differences between groups $(P=0.35)$ (Table 2). Intensive or tight fibrosis (score 4 and 5) was observed in 2 rabbits (13\%) in group 1, in 5 rabbits $(33 \%)$ in group 2 , and in 3 rabbits $(20 \%)$ in group 3, and the difference between groups was not statistically significant $(P=0.41)$.

Histopathological images of inflammation classifications is shown in Fig. 4. The percentages of the inflammation scores of the rabbits in group 1 for score 2, 3, 4, and 5 were $60 \%(n=9)$,

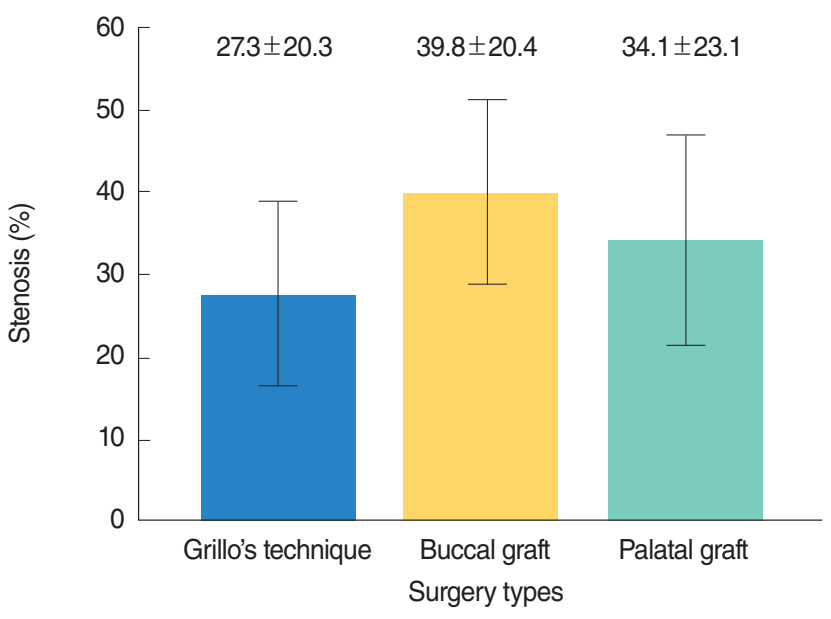

Fig. 2. Percentages of stenosis at the completion of the study.
$20 \%(n=3), 14 \%(n=2)$, and $7 \%(n=1)$, respectively. In group 2 rabbits, inflammation scores $2,3,4$, and 5 were observed 5 (33\%), $3(20 \%), 4(27 \%)$, and $3(20 \%)$, respectively. Histopathological inflammation scores were as follows for the rabbits in group 3: $7(47 \%)$ in scores 2; $5(33 \%)$ in scores 3; $2(13 \%)$ scores 4 ; and $1(7 \%)$ scores 5 . The difference was not statistically significant $(P=0.21)$ (Table 2). Excessive inflammation (score 4 and 5) was observed in 3 rabbits (20\%) in group 1, in 7 rabbits $(47 \%)$ in group 2, and in 3 rabbits $(20 \%)$ in group 3 . The difference between groups was not statistically significant although inflammation rate was higher among the rabbits which were applied buccal mucosa graft $(P=0.18)$.

\section{DISCUSSION}

Although benign sub-glottic stenosis is occurred due to different reasons, it is a complex problem of which treatment is challenging. Many treatment modalities have been tried since decades. Stent applications which is added to laser and dilation treatment, local application of the fibroblast proliferation-inhibiting agents like mitomycin $\mathrm{C}$ may be an alternative. Surgical options represent in a wide range including laryngoplasty from partial cricoid cartilage together with segmental resection. However no randomized trials are available showing which treatment option should be preferred.

Approximation of the robust margins through a meticulous
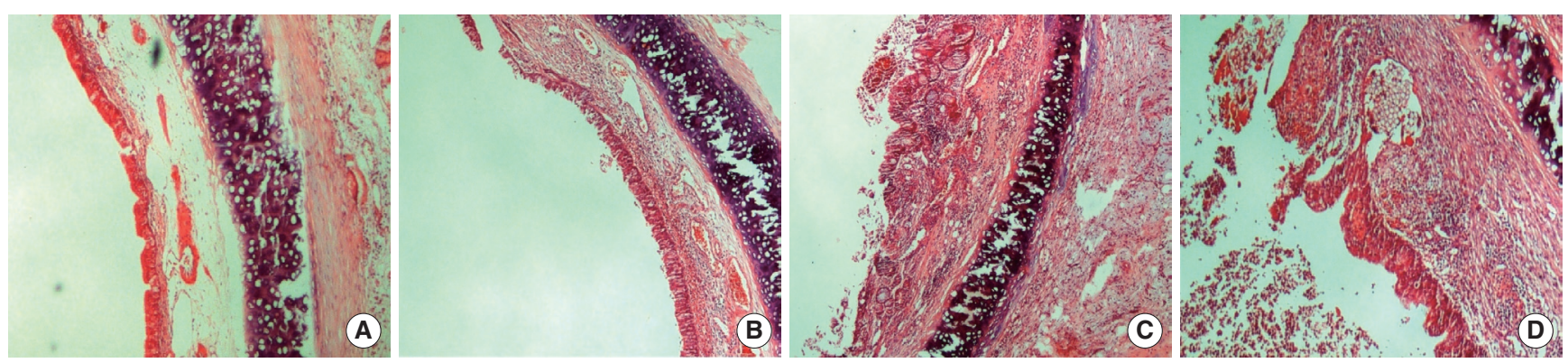

Fig. 3. The histopathological views of fibrosis scores in the samples taken from subglottic area of rabbits. (A) Score 2, (B) score 3, (C) score 4 , and (D) score 5.
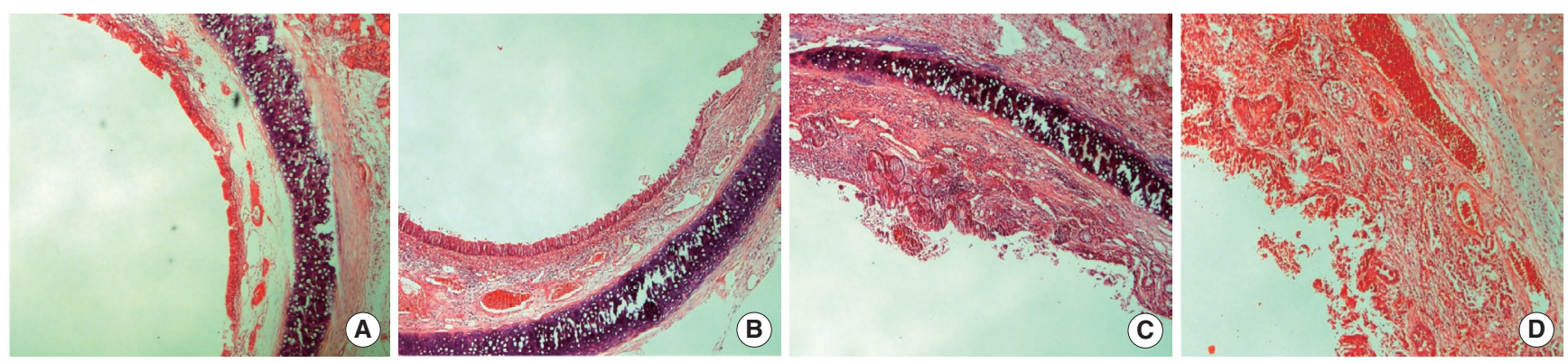

Fig. 4. The histopathological views of inflammation scores in the samples taken from subglottic area of rabbits. (A) Score 2, (B) score 3, (C) score 4 , and (D) score 5. 
muco-mucosal anastomosis is one of the key points of the success in patients who undergo tracheal surgery [10]. Pioneers of tracheal surgery have developed their own techniques in order to approximate the robust mucosal margins. Actually, each technique has unique advantages. The different techniques defined by Grillo [4] and Pearson [11] include the posterior surface of cricoid cartilage being covered by the robust tracheal mucosa on distal. Macchiarini et al. [12] modified these techniques, made an oblique excision of cricoid cartilage and cricoid membrane, used a continuous suture in the posterior surface. Montgomery [5] widened the cricoid cartilage with a graft and preferred to use a mucosal graft. Liberman and Mathisen [6] used a mucosal graft in their modified tailored cricoplasty method. Sufficient data is not available about the use of palatal mucosa in trachea surgery. However palatal mucosa graft has the ease of use and its not losing its integrity during grafting due to its thickness may provide an advantage for using it in sub-glottic field [13]. Palatal mucosa is resistant to contracture $[7,14,15]$. Also it is rapidly vascularized after grafting as it has a keratinized epithelium [15].

This randomized prospective experimental study showed that palatal mucosa graft is as effective as the techniques which include buccal mucosa graft and apply posterior mucosal trachea flap. Although a better wound healing was detected in palatal mucosa graft group compared to group 2, the difference was not statistically significant. Both tracheal mucosa flap and free mucosal flap would be supplied from cricoid base. Sufficient removal of fibrotic tissue would provide a better vascular supply for the mucosal tissue. Laryngo-tracheal resection techniques are usually more successful than the laryngoplasties which do not include segmental resection [16]. This shows the importance of removal of the whole fibrotic tissue. For this purpose, Liberman and Mathisen [6] recommended to obtain a cricoid base which does not include a new fibrotic tissue through total removal of the fibrotic tissue with a sharp dissection instead of looking for a dissection plane between cricoid cartilage and the granulation tissue.

Another reason for anastomosis failure in trachea surgery is the length of the resected segment [17]. Increased anastomosis tension reduces the success of anastomosis [3,17]. Suprahyoid release proposed by Montgomery [18] is easily applied and an effective method. An end-to-end anastomosis cannot be made between thyroid cartilage and trachea in the methods which use free mucosa graft, instead a direct end-to-end anastomosis is made between the cricoid ring which gained mucosa again and trachea. So a 7-10 mm more distance is provided and the tension at anastomosis line may be reduced. Moreover, grafting methods enable the cricoid field enlarge with the cartilage grafts instead of narrowing it. There are no studies comparing the two techniques exist in the literature. This study showed that there were no statistically significant difference between methods which use free mucosa graft and direct end-to-end anastomosis methods. The techniques with mucosal graft applications did provide an advantage or disadvantage in results of our study. This may have arisen from the absence of a difference between anastomosis tensions between surgery groups due to the anatomy of the rabbits.

The attempts of tracheal replacement with free non-vascularized grafts have failed [19]. Lack of revascularization is often the reason of failure [20]. Even in tracheal reimplantations made with short segment non-vascularized grafts, cartilage is resorbed and it is replaced by fibrous tissue [19]. When nasal and ear cartilages are used at laryngotracheoplasty, they are rapidly resorbed and can not provide the essential mechanical support [21]. Similarly, necrosis was also determined at the costal cartilage grafts in the early stages [22]. De Jong et al. [23] showed that the most appropriate cartilage graft tissue is thyroid cartilage graft. In the development of tracheolaryngeal surgery to date, especially vascularized grafts should be prefered for the patients that will be applied autograft methods for long segment. There are some studies show that vascularized homografts including omentopexy, muscle flaps and myocutaneous flaps were found successfully [24-27]. Unfortunately, this studies had short-term follow-up generally and the results of the most of them were with limited success [16,19]. Tissue engineering studies hold promise for both closing the tracheal defects and the replacement of trachea [19,28,29]. Shin et al. [29] showed that allogenic chondrocytes culture was successfully applied in an experimental model. They explained that disadvantages of their procedure could not provide the required mechanical strength when applied to circumferential or large tracheal defects [29]. Another limitations of their technique is the lack of epithelial cell implantation. Despite the advances in tissue engineering, especially failure to provide vascularization of extracellular matrix continues to create challenges [19]. Tracheal replacement in the patients with laryngotracheal stenosis is only indicated when treating with end-to-end anastomosis is not possible [19]. Tracheal resection and end-to-end anastomosis is still first option in the patients with benign laryngotracheal stenosis [16]. Suggesting a safe limit for segmentary resection of trachea is $4.5 \mathrm{~cm}$ in adults [17]. The toleration of pediatric patients is less than adults. It is recommended that limit of segmental resection should not be exceed $30 \%$ of tracheal length [30]. Therefore, each millimeters of the trachea is important in the patients underwent tracheal surgery. Some cases may be prevented from going into the complex surgery by doing cricoidoplasty with mucosal grafts. When the original tissue and circulation is preserved, to apply to the mucosal grafts may help to prevent to the formation of granulation in the laryngo-tracheal area.

This study is important as it shows the effective use of palatal graft in trachea surgery. However it may have some limitations. Most of them were resulted from the anatomy of rabbits. First, palatal mucosa of rabbits is serrated, so palatal mucosa grafts were thinned more and grafted tightly, differently from humans. 
This tension may have reduced the success of the graft through causing contracture. Second, cricoid membrane distance is proportionally longer in rabbits, so the cartilage graft used to enlarge the cricoid ring could have not provide an adequate enlargement. Third, the sutures in the cartilage ring could have been done full thickness, not sub-mucosal due to the fragility of trachea cartilage. Fourth, $\mathrm{T}$ tube was not applied. Silicon $\mathrm{T}$ tube of Montgomery [31] is frequently used in the techniques which use cartilage and mucosa graft. T tube enables the regular epithelization of mucosa and also it works as a stent against the narrowing in the early period. We may state that mucosal graft techniques would be more effective when applied under optimal conditions based on our results which we obtained without using $\mathrm{T}$ tube. Except for the limitations of the surgical technique, another problem is that there is no statistical difference between the graft of palatal mucosa and the graft of buccal mucosa. Despite the palatal graft is found partially better in all objective data, the inability to show statistical differences may also be due to insufficient number of subjects.

In conclusion, meticulous end-to-end anastomosis of the mocusa and removal of the whole fibrotic tissue are the factors which increase success in each surgical method used in treatment of sub-glottic stenosis. Up to $50 \%$ segment resection of trachea and end-to-end anastomosis of trachea are generally possible, but this varies depending on patients' anatomical neck structure, age, and history of previous surgery. Cases that endto-end anastomosis techniques were not applied to, are candidate for the complex tracheal replacement surgery. Doing cricoidoplasty with mucosa and cartilage graft provides to gain a little more distance for end-to-end anastomosis. Although our results are not statistically significant, it has been seen that palatal mucosa graft gives better results than buccal mucosa graft in cricoidoplasty. This study showed the feasibility of free palatal mucosa grafts in sub-glottic field, one of the most challenging fields of trachea surgery, with ease of application and rapid vascularization.

\section{CONFLICT OF INTEREST}

No potential conflict of interest relevant to this article was reported.

\section{REFERENCES}

1. Haft S, Lee JY, Ghosh A, Philiponis G, Malaisrie N, Leahy KP, et al. Inflammatory protein expression in human subglottic stenosis tissue mirrors that in a murine model. Ann Otol Rhinol Laryngol. 2014 Jan;123(1):65-70.

2. Rubikas R, Matukaitytè I, Jelisiejevas JJ, Rackauskas M. Surgical treatment of non-malignant laryngotracheal stenosis. Eur Arch Otorhinolaryngol. 2014 Sep;271(9):2481-7.
3. Gomez-Caro A, Morcillo A, Wins R, Molins L, Galan G, Tarrazona V. Surgical management of benign tracheal stenosis. Multimed Man Cardiothorac Surg. 2011 Jan;2011(1111):mmcts.2010.004945.

4. Grillo HC. Primary reconstruction of airway after resection of subglottic laryngeal and upper tracheal stenosis. Ann Thorac Surg. 1982 Jan;33(1):3-18.

5. Montgomery WW. Chronic subglottic stenosis. Otolaryngol Clin North Am. 1984 Feb;17(1):107-13.

6. Liberman M, Mathisen DJ.Tailored cricoplasty: an improved modification for reconstruction in subglottic tracheal stenosis. J Thorac Cardiovasc Surg. 2009 Mar;137(3):573-8.

7. Holck DE, Foster JA, Dutton JJ, Dillon HD. Hard palate mucosal grafts in the treatment of the contracted socket. Ophthal Plast Reconstr Surg. 1999 May;15(3):202-9.

8. Myer CM 3rd, O'Connor DM, Cotton RT. Proposed grading system for subglottic stenosis based on endotracheal tube sizes. Ann Otol Rhinol Laryngol. 1994 Apr;103(4 Pt 1):319-23.

9. Iniguez-Cuadra R, San Martin Prieto J, Iniguez-Cuadra M, Zuniga Erranz S, Jofre Pavez D, Gonzalez Bombardiere S, et al. Effect of mitomycin in the surgical treatment of tracheal stenosis. Arch Otolaryngol Head Neck Surg. 2008 Jul;134(7):709-14.

10. Couraud L, Jougon JB, Velly JF. Surgical treatment of nontumoral stenoses of the upper airway. Ann Thorac Surg. 1995 Aug;60(2):2509.

11. Pearson FG. Technique of management of subglottic stenosis. Chest Surg Clin NAm. 1996 Nov;6(4):683-92.

12. Macchiarini P,Verhoye JP, Chapelier A, Fadel E, Dartevelle P. Partial cricoidectomy with primary thyrotracheal anastomosis for postintubation subglottic stenosis. J Thorac Cardiovasc Surg. 2001 Jan; 121(1):68-76

13. Aydogmus U, Turk F, Yuncu G. Surgical repair with palatal mucosal graft in subglottic stenosis caused by Wegener's granulomatosis. Turk Gogus Kalp Damar Cerrahisi Dergisi. 2015;23(3):595-600.

14. Hatoko M, Tanaka A, Kuwahara M, Yurugi S, Niitsuma K, Iioka H. Influence of periosteum on donor healing after harvesting hard palate mucosa. Ann Plast Surg. 2003 Jan;50(1):25-30.

15. Cohen MS, Shorr N. Eyelid reconstruction with hard palate mucosa grafts. Ophthal Plast Reconstr Surg. 1992 Sep;8(3):183-95.

16. Yamamoto K, Kojima F, Tomiyama K, Nakamura T, Hayashino Y. Meta-analysis of therapeutic procedures for acquired subglottic stenosis in adults. Ann Thorac Surg. 2011 Jun;91(6):1747-53.

17. Wright CD, Grillo HC, Wain JC, Wong DR, Donahue DM, Gaissert $\mathrm{HA}$, et al. Anastomotic complications after tracheal resection: prognostic factors and management. J Thorac Cardiovasc Surg. 2004 Nov;128(5):731-9.

18. Montgomery WW. Suprahyoid release for tracheal anastomosis. Arch Otolaryngol. 1974 Apr;99(4):255-60.

19. Haykal S, Salna M, Waddell TK, Hofer SO. Advances in tracheal reconstruction. Plast Reconstr Surg Glob Open. 2014 Aug;2(7):e178.

20. NevilleWE, Bolanowski PJ, Soltanzadeh H. Homograft replacement of the trachea using immunosuppression. J Thorac Cardiovasc Surg. 1976 Oct;72(4):596-601.

21. Weisberger EC, Nguyen CT. Laryngotracheal reconstruction using a Vitallium alloy miniplate. Ann Otol Rhinol Laryngol. 1996 May; 105(5):363-6.

22. Carron JD, Greinwald JH, Oberman JP, Werner AL, Derkay CS. Simulated reflux and laryngotracheal reconstruction: a rabbit model. Arch Otolaryngol Head Neck Surg. 2001 May;127(5):576-80.

23. De Jong AL, Park AH, Raveh E, Schwartz MR, Forte V. Comparison of thyroid, auricular, and costal cartilage donor sites for laryngotracheal reconstruction in an animal model. Arch Otolaryngol Head Neck Surg. 2000 Jan;126(1):49-53.

24. Hirata T, Yamazaki F, Fukuse T, Muro K, Yokomise H, Inui K, Takahashi Y, et al. Omentopexy for revascularization of free tracheal 
grafts in rats. Thorac Cardiovasc Surg. 1992 Aug;40(4):178-81.

25. Kumaran S, Nambi GI, Kingsly Paul M, Gupta AK. Post-electricalburn tracheal-defect reconstruction with pre-fabricated deltopectoral flap: a case report. J Plast Reconstr Aesthet Surg. 2009 May;62 (5):e93-4.

26. He J, Xu X, Chen M, Li S, Yin W, Wang S, et al. Novel method to repair tracheal defect by pectoralis major myocutaneous flap. Ann Thorac Surg. 2009 Jul;88(1):288-91.

27. Masuda M, Kamizono K, Ejima M, Fujimura A, Uryu H, Kadota H. Tracheal reconstruction with a modified infrahyoid myocutaneous flap. Laryngoscope. 2012 May;122(5):992-6.
28. Tan Q, Steiner R, Hoerstrup SP, Weder W. Tissue-engineered trachea: History, problems and the future. Eur J Cardiothorac Surg. 2006 Nov;30(5):782-6.

29. Shin YS, Lee BH, Choi JW, Min BH, Chang JW, Yang SS, et al. Tissueengineered tracheal reconstruction using chondrocyte seeded on a porcine cartilage-derived substance scaffold. Int J Pediatr Otorhinolaryngol. 2014 Jan;78(1):32-8.

30. Wright CD, Graham BB, Grillo HC, Wain JC, Mathisen DJ. Pediatric tracheal surgery. Ann Thorac Surg. 2002 Aug;74(2):308-13.

31. Montgomery WW. T-tube tracheal stent. Arch Otolaryngol. 1965 Sep;82(3):320-1. 